\title{
A SPECTRAL APPROACH TO MOHO DEPTHS ESTIMATION FROM GRAVITY MEASUREMENTS IN EPIRUS (NW GREECE)
}

\author{
Gerasimos-Akis Tselentis, ${ }^{1,}{ }^{*}$ John Drakopoulos, ${ }^{2}$ \\ and Klisthenis Dimitriadis ${ }^{2}$ \\ ${ }^{1}$ Earthquake Research Institute, The University of Tokyo, \\ Bunkyo-ku, Tokyo 113, Japan \\ ${ }^{2}$ Department of Geophysics, Athens University, \\ Panepistimiopolis Athens 157 84, Greece
}

(Received January 7, 1988; Revised November 16, 1988)

\begin{abstract}
We compute crustal thickness in Epirus (NE Greece), from spectral analysis of the Bouguer gravity field.

Moho depths were established from the slope of the log-power radial spectrum at the lower end of the wavenumber band and were found to vary from 31 to $38 \mathrm{~km}$.

This is in agreement with the results obtained by other investigators employing seismological methods of analysis.
\end{abstract}

\section{Introduction}

A two-dimensional set of data representing a potential field such as the gravity field, can be thought of as a superposition of fields due to a subsurface distribution of sources. Consequently, linear methods such as two-dimensional filtering should be of use in separating the various components according to their wavenumber spectrum.

Spectral methods of gravity data processing are being increasingly employed in recent years, owing to their elegance in handling a large amount of data and their built-in mechanism for signal-to-noise ratio enhancement (BHATTACHARYYA and LEU, 1975).

By Fourier transformation, the gravity field data can be represented by twodimensional Fourier series consisting of various frequencies which characterize the anomalies. The amplitude and phase relationship among these frequencies has been used extensively by many workers for the interpretation of gravity data, particulary in the case of downward continuation and source depth estimation (SPECTOR and Grant, 1970; Treitel et al., 1971; Green, 1972; Hahn et al., 1976; PÁl et al., 1979; Negi et al., 1983; Bose and SenGUPTA, 1984).

Representing the Moho by a variable interface, $h(x)$, and considering a

* Present address: Athens University, Panepistimiopolis Athens 157 84, Greece. 
constant density contrast, $P_{\mathrm{o}}$, the Fourier transform of the corresponding gravity field can be written (MisHRA and PEDERSEN, 1982):

$$
\Delta g(k)=\left(2 G P_{0} / k\right) \int_{-\infty}^{\infty} \mathrm{e}^{-j k x} \mathrm{e}^{-|k| h(x)} \mathrm{d} x
$$

where, $k$ is the wavenumber ( $=1 /$ wavelength), and $G$ is the international gravity constant.

Expanding the exponential and taking into account only the first order term which is a very good approximation for the small wavenumbers that we are interested in, the above relation can be written:

$$
\Delta g(k)=2 G P_{0} \mathrm{e}^{-j|k| h_{\mathrm{o}}} \Delta h(k)
$$

indicating a direct connection between the computed gravity spectra and the unknown mean depth, $h_{\mathrm{o}}$, of the interface, perturbated by the term $\Delta h(k)$.

At the long wavelengths in which we are interested the non-linear effect of $\Delta h(k)$ is negligible (Mishra and PEDERSEN, 1982), and the relation between gravity spectra and depth is almost log-linear. Thus, the slope of the graph provides an estimate of the depth.

For the case of two-dimensional data, it is convenient to work with the absolute value of the radial spectrum of all the partial waves falling within a frequency range, as will be explained in section 3.

\section{Tectonics and Geology of the Area}

The area of Epirus lies along the North-Western margin of the Greek mainland, extends into SW Albania, and is situated along the Apullian and Aegean blocks (Fig. 1).

The rocks present in the area are divided into the Ionian depositional zone and its subzone (Gavrovo). The Adriatic-Ionian zone begins from Tirana in Albania and extends along the study area down to NW Peloponnese. It is made up of rocks ranging in age from Triassic (evaporitic facies) to upper Neocen (I.F.P., 1966). These are mainly pelagic limestones followed by silts, sandstones, and conglomerates of typical flysch facies of Miocene age.

The subzone of Gavrovo is exposed east of the Ionian zone and consists of thick, mainly neritic limestones protruding through the flysch. Upper Eocene limestones lie disconformably upon Cretaceous limestones.

From Eocene time until the end of the Tertiary, detrital sediments accumulated in the area, reaching a few thousand meters above the Triassic evaporites. Significant tectonic activity started in the subzone of Gavrovo in the Oligocene, and in the Ionian zone in the Middle Miocene (I.F.P., 1966). This activity created folds and thrust faults that generally strike NW-SE (Fig. 1).

The SW migration of deformation and fault plane solutions from a few moderate earthquakes near the Ionian coast (Drakopoulos and Delibasis, 1974; 

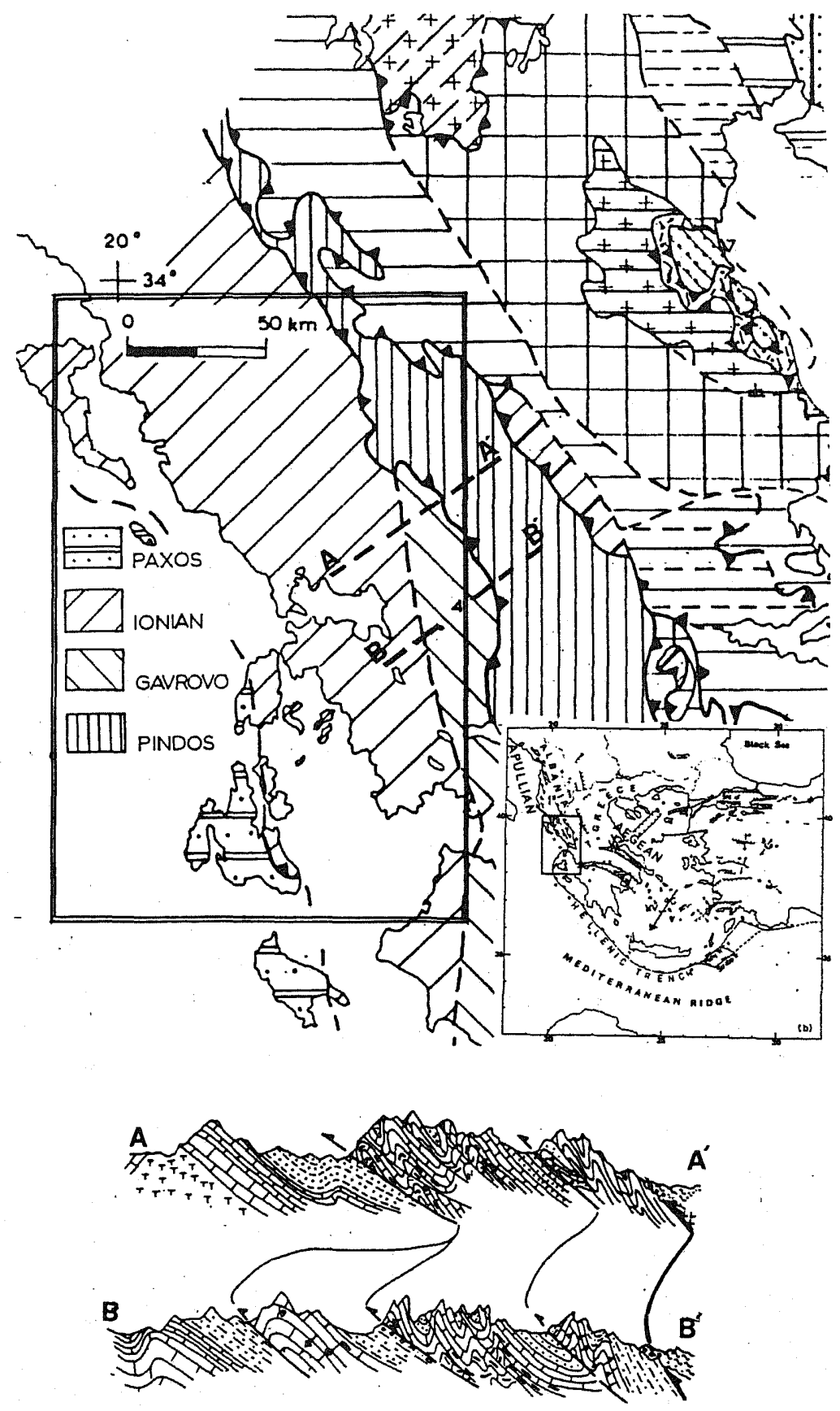

Fig. 1. Tectonic setting of the general area, illustrating the tectonic zones encountered. 
Papazachos et al., 1984), together with studies of late Cenozoic deformation (MERCIER et al., 1979), suggest that the tectonic activity results from the collision and continuing North-Westward convergence of the Northern Ionian sea floor, which is affected by the tectonic development of the Aegean region (LE PICHON and ANGELIER, 1979; BURCHFIELD, 1980).

The tectonic framework of the area is mainly compressive, characterized by numerous zones of thrust faulting striking parallel to the coast (Fig. 1), with earthquakes showing a predominant compressive stress component.

However, some seismic events have been attributed to normal faulting (Drakopoulos and Delibasis, 1974; MCKenzie, 1978) and a recent microearthquake survey in the area (KING et al., 1983) revealed that the derived fault plane solutions exhibit a variety of focal mechanisms, which are not consistent with simple zones of shortening or extension.

Additionally, a number of in situ stress measurements in the area (PAQUIN et al., 1984), indicate the presence of a dominant E-W extensional stress regime.

\section{Method of Analysis}

The Bouguer map of Epirus, prepared by MAKRIS (1977), has been used in the present investigation. The area was surveyed gravimetrically during the years 19711973 (Fig. 2), with a survey density of 0.075 stations $/ \mathrm{km}^{2}$.

The data were uniformly reduced to Bouguer anomalies at mean sea level, and topographic reductions from 0 to $166.7 \mathrm{~km}$ were computed on a spherical earth with a uniform density of $2.67 \mathrm{~g} / \mathrm{cm}^{3}$.

The whole map was digitized and the data were gridded using a modified version of an interpolation algorithm written by SwAIN (1976) which uses finite difference equations to produce a system with minimum curvature. The resulting grid was then contoured and inconsistent data were identified by the tight circular contours they produced and were removed from the data file.

Eight square grids, measuring $160 \times 160 \mathrm{~km}$ each $(32 \times 32$ data points) and overlapping by $50 \%$ were used for the calculation of Moho depths across a N-S direction.

For each square grid, the following operations were performed. First, we removed the regional field by fitting a plane surface to all the data by the method of least squares. The obtained regional field was found to be described by the expression:

$$
f(x, y)=-3.985 x+1.068 y+0.827
$$

where $x$ and $y$ are the two axes of the grids.

The residual gravity field values for each block were then transformed from the space domain to the frequency domain by means of a Fast Fourier Transform (FFT).

Applying an FFT algorithm to the above data subgrids will obviously cause a 


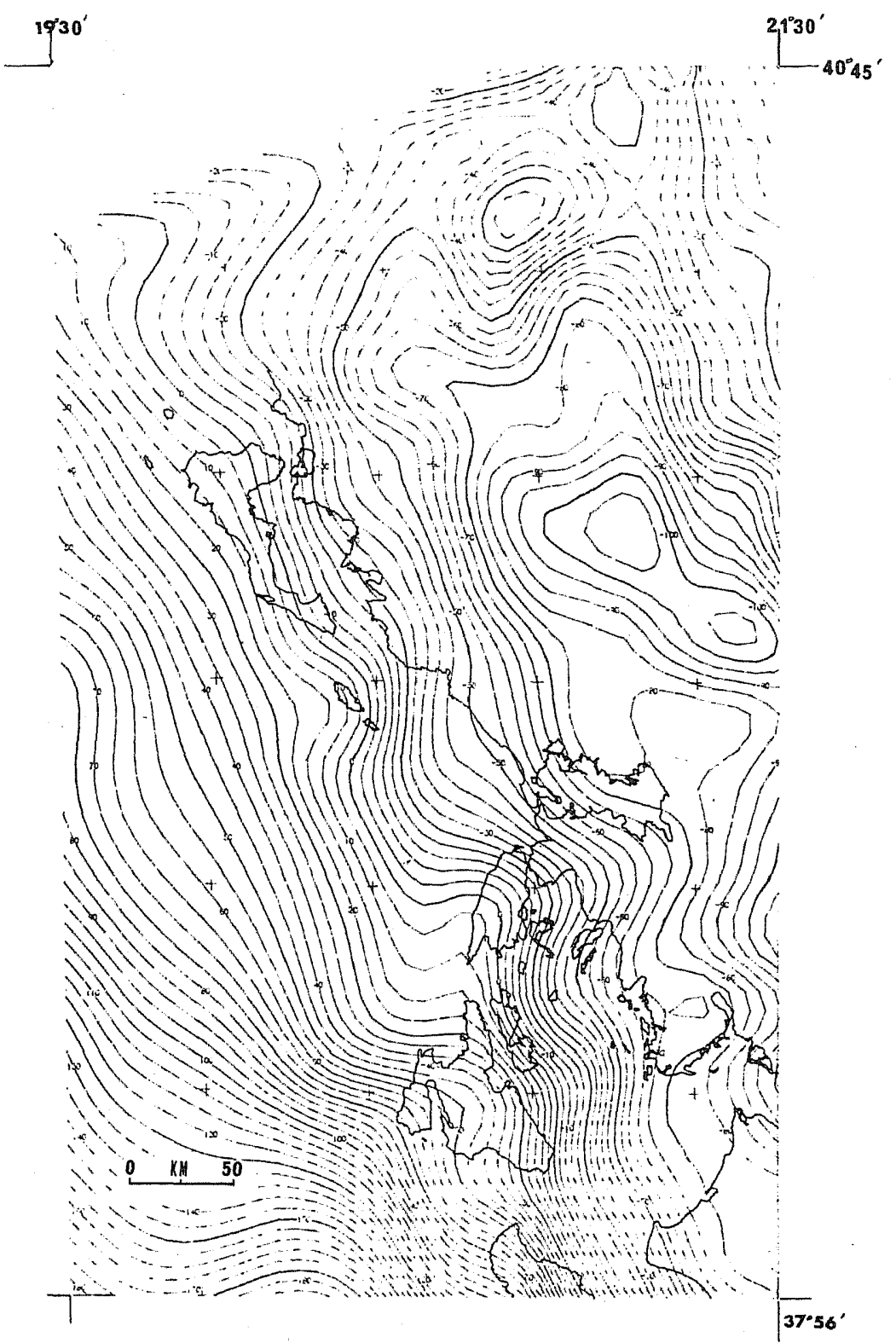

Fig. 2. Bouguer gravity map of the investigated area. Contour interval is $5 \mathrm{mgal}$.

pronounced Gibbs phenomenon leading to great edge effects. In order to make transition zones wider, we used the following procedure (BHATTACHARYYA and LEU, 1975).

We assume that the residual field vanishes at the points located a distance of 


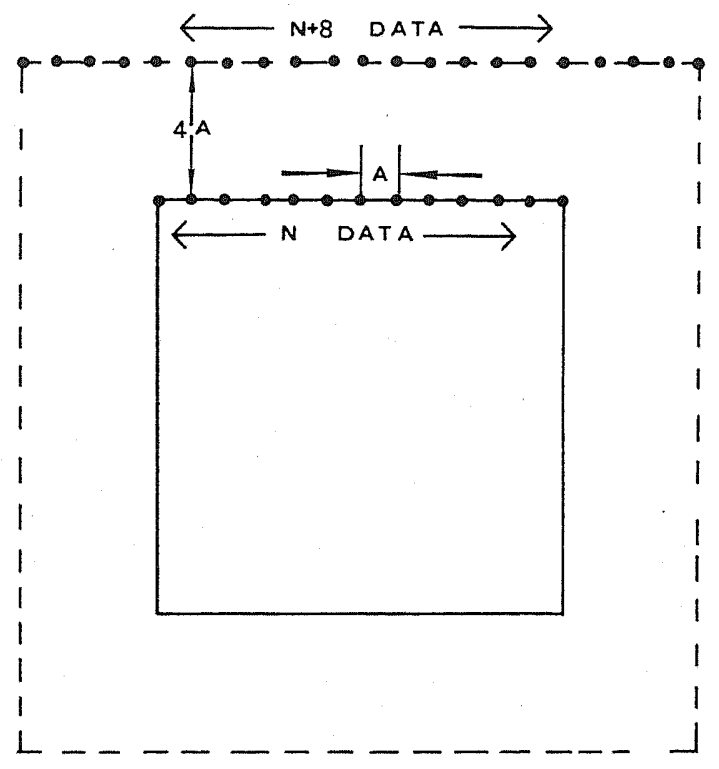

Fig. 3. Data expansion scheme.

four units of the data spacing from the boundary of each subgrid. Inclusion of these points results in $(N+8) \times(N+8)$ non-equispaced data points for an $N \times N$ block (Fig. 3). Next, bicubic spline surfaces were fitted to the data by employing the finite element technique (INOUE, 1986) in such a way that the residual field and the continuity of the first and second derivatives are maintained at each one of the data points. These surfaces, were used to generate the "tapered" data set.

The Fourier transform of each data grid results in a set of Real $R_{m}$ and Imaginary $I^{k}$ amplitudes by means of which the field values given at the grid points $(x, y)$ can be represented by the sum:

$$
\begin{aligned}
g(x, y)= & \sum_{k} \sum_{m} R_{m}^{k} \cos \{2 \pi /(D X N)(k x+m y)\} \\
& +I_{m}^{k} \sin \{2 \pi /(D X N)(k x+m y)\}
\end{aligned}
$$

where $D X$ is the grid interval.

Equation 4 can be written as follows:

$$
g(x, y)=\sum_{k} \sum_{m} C_{m}^{k} \cos \left\{2 \pi /(D X N)(k x+m y)-P_{m}^{k}\right\}
$$

where $P_{m}^{k}$ is the appropriate phase angle and

$$
C_{m}^{k}=\left\{\left(R_{m}^{k}\right)^{2}+\left(I_{m}^{k}\right)^{2}\right\}^{1 / 2}
$$

is the amplitude of a partial field wave, with wavelength $D X \cdot N /\left(k^{2}+m^{2}\right)^{1 / 2}$ and frequency $F_{m}^{k}=\left(k^{2}+m^{2}\right)^{1 / 2}$. 


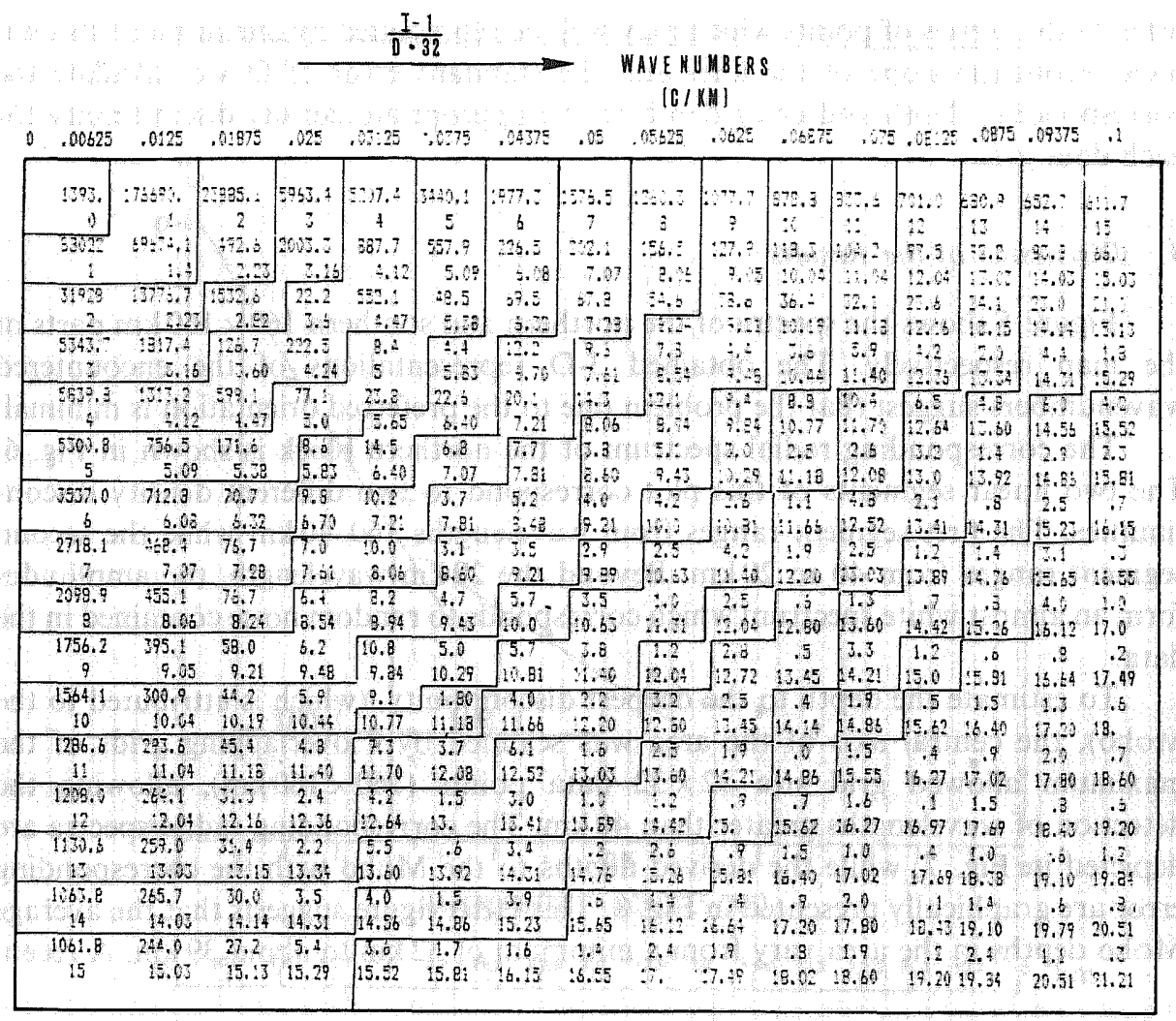

Fig. 4. Schematic computation of the radial spectrum for the northern $160 \times 160 \mathrm{~km}$ block. Spectrum matrix coefficients $C_{m}^{k}$ are also shown.

In order to calculate the radial spectrum for each data grid, we calculate first the 2-D power spectrum:

$$
P(I, J)=R(I, J)^{2}+I(I, J)^{2} .
$$

The radial spectrum is calculated by superposing the $2-\mathrm{D}$ spectrum with a number of concentric rings that are centered at $[1,1]$, (upperleft point of the matrix $P(I, J)$, which is the lowest frequency component of the data set (mean value), and with radial distances described in Fig. 4. Next, the squares of the amplitudes of the partial waves occurring between two consecutive cycles are averaged.

The scheme for computing radial spectra for the northern $160 \times 160 \mathrm{~km}$ data grid is illustrated in Fig. 4. The resulting values form the radial spectrum of the anomalous field under consideration, and are normalized to the value $\mathrm{Co}(1,1)$. By this technique, we transform the current two-dimensional problem to a onedimensional one, assuming no preferred orientation in the response.

If the logarithms of such a radial spectrum are plotted against frequency, one 
often finds a series of points which may well be represented by one or more straight lines. From the slope of the lines and the standard error of fit we calculate the corresponding depth and error depth to the appropriate density discontinuity for each data grid.

\section{Discussion of the Results}

Figure 5 shows the spectra of the northern and southern $160 \times 160 \mathrm{~km}$ parts of the map respectively. The obtained 3-D representations of the encountered wavenumbers suggest that the problem due to the preferred orientation is minimal.

The corresponding radial spectrum of the northern block is shown in Fig. 6 . The two linear segments of this plot correspond to two different density discontinuities. The first segment ranges from wavelengths $160-40 \mathrm{~km}$ while the second segment ranges from 40 to $20 \mathrm{~km}$. Beyond the $20 \mathrm{~km}$ wavelength, the amplitudes form an almost white spectrum which corresponds to random noise contained in the data.

To estimate the depth to the deepest discontinuity, (which is attributed to the Moho), the central axis of the area was scanned by 8 overlapping grids of the maximum allowed grid size $32 \times 32$ data points $(160 \times 160 \mathrm{~km})$, allowing the detection of wavelengths greater than $40 \mathrm{~km}$. The corresponding radial spectra are depicted in Fig. 7, while the derived depths to the Moho with the corresponding error are graphically presented in Fig. 8. This latter figure suggests that the average Moho depths in the area vary from a minimum of $32 \mathrm{~km}$ to about $39 \mathrm{~km}$. A recent

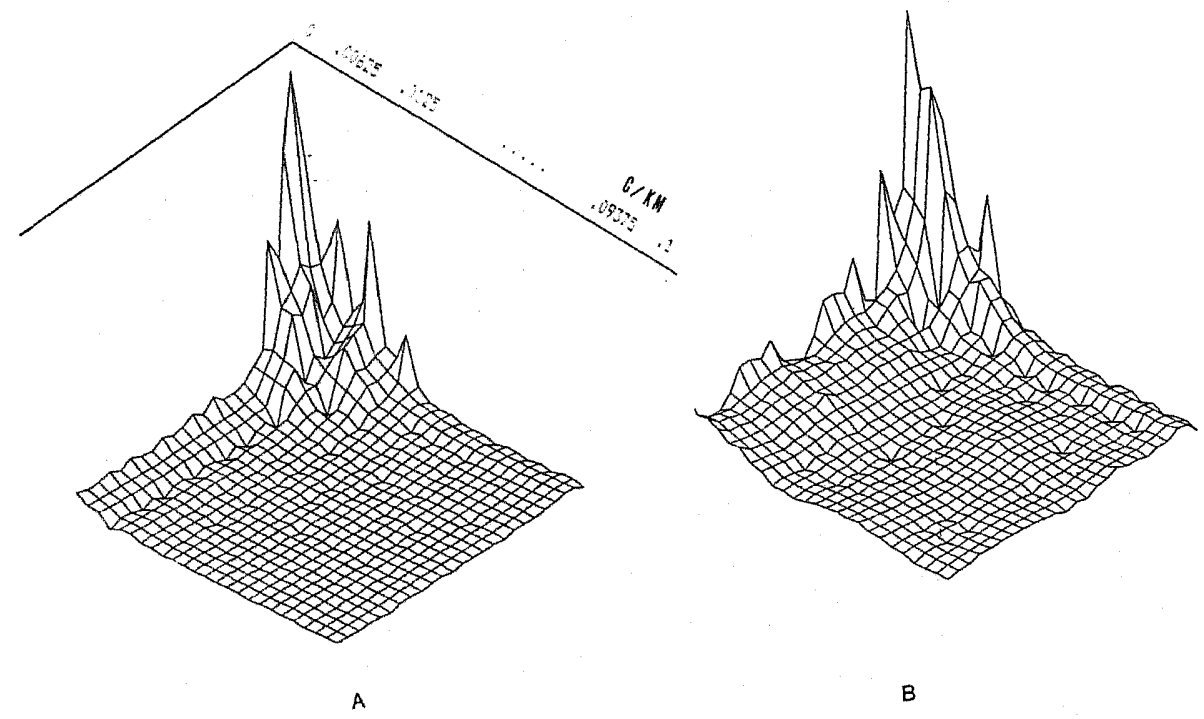

Fig. 5. Three-dimensional representation of the encountered wavenumbers for the northern (A), and the southern (B) blocks. 


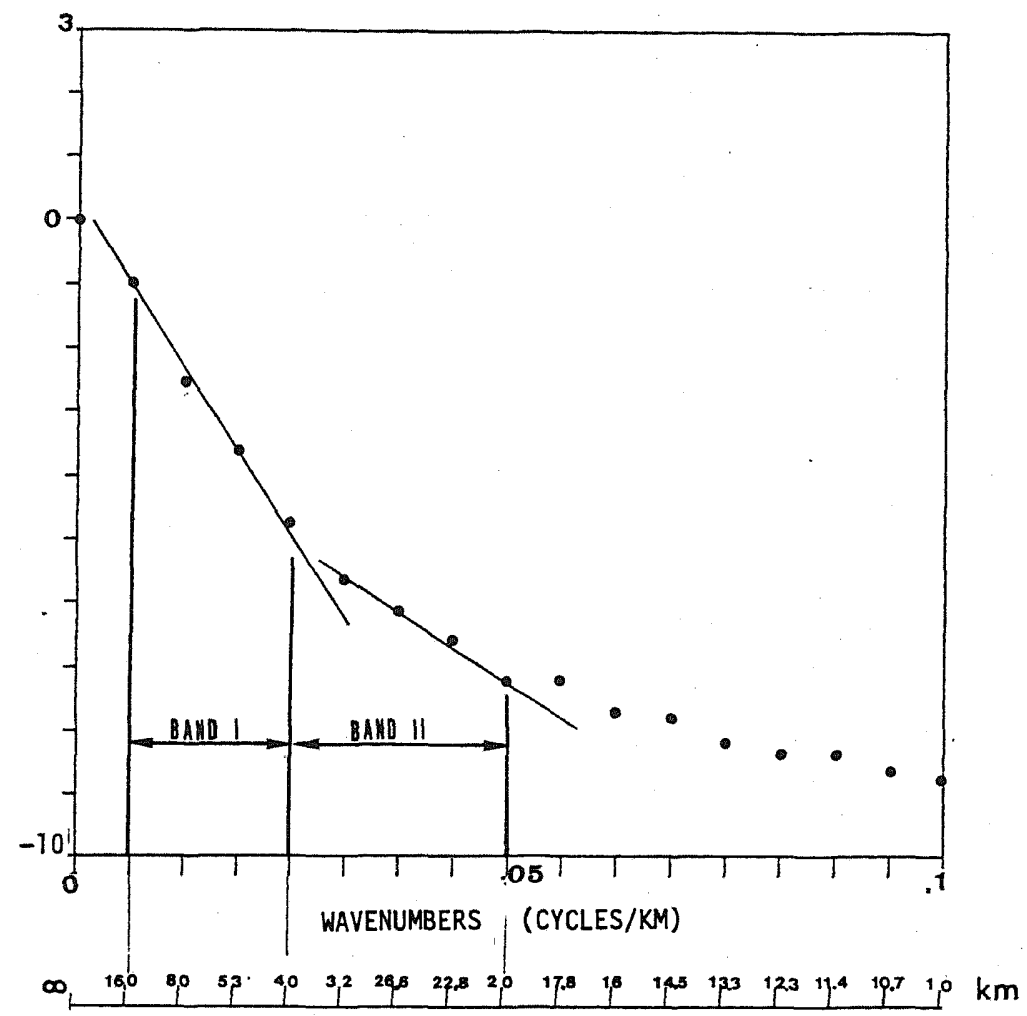

Fig. 6. Radial spectrum for the northern block.
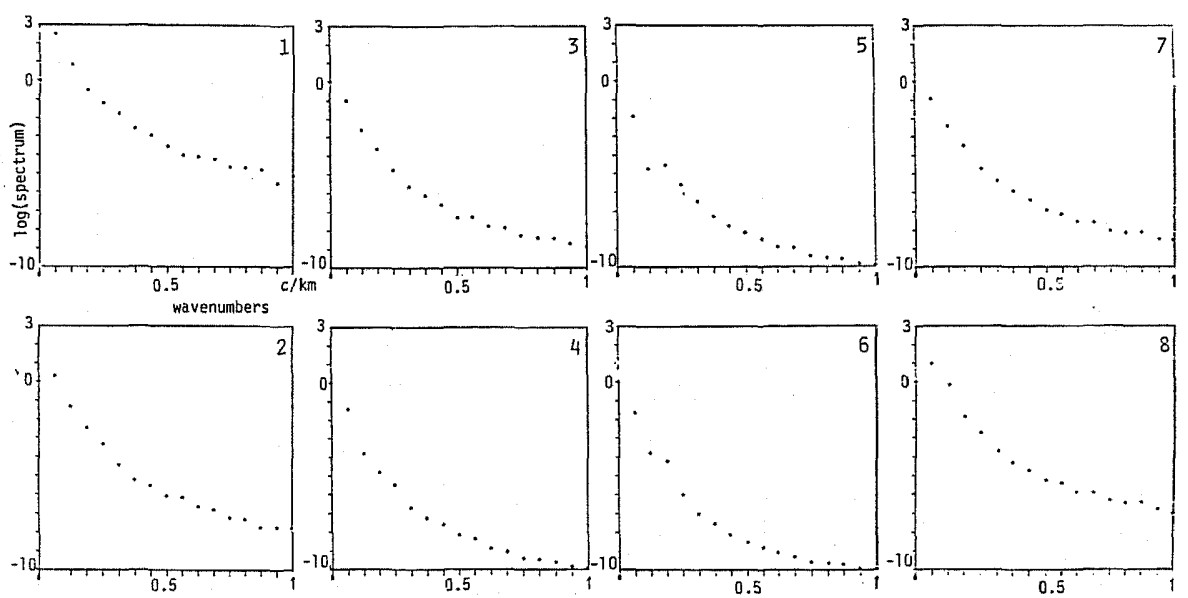

Fig. 7. Radial spectrum for the eight grids used for Moho depths estimation. 


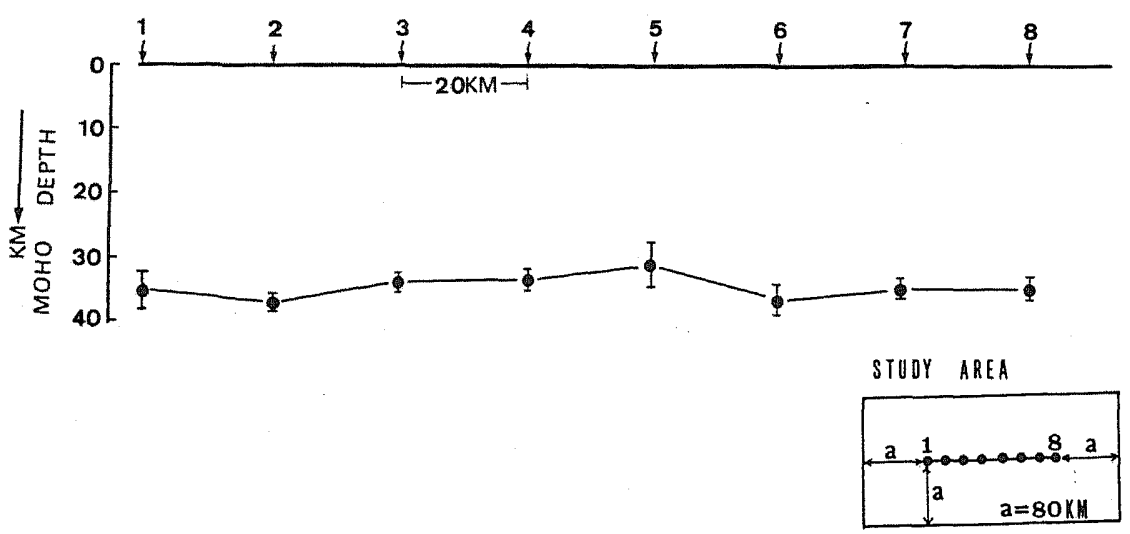

Fig. 8. Moho depths traverse along (N-S) Epirus with associated errors. Points $1,2, \cdots, 8$ represent the centers of the $160 \times 160 \mathrm{~km}$ grids used for the scan.

investigation in the area employing the analysis of $P_{g}$ and $P_{n}$ waves (Karacostas, 1982), suggested a crustal thickness of the order of $40 \mathrm{~km}$, while an application of a single station deconvolution to long-period P-waves resulted in a crustal thickness of about $35 \mathrm{~km}$ (TSELENTIS and Drakopoulos, 1988). These results seem to be in good agreement with the results obtained from the present analysis.

\section{Accuracy of the Results}

One cause of discrepancy in the results might be found in the effect that every unit of buried mass contributes to the total observed gravity field, thus the spectral overlap between the effect of deeper and shallower sources will always occur.

Care also has to be taken to minimize aliasing errors caused by digitization. Obviously, closer digitization has the effect of incorporating high frequency components, resulting in the decrease of the slope of the log spectral curve (SPECTOR, 1968).

One difficulty with this refinement occurs because the higher wavenumber components tend towards increasingly smaller magnitudes and it becomes hard to separate them from noise. The overall effect is that the derived depths will be underestimated. Increasing digitization on the other hand leads to aliasing errors, hence an optimization of digitization spacing is essential.

\section{Conclusion}

As part of an extensive geophysical investigation in the area of Epirus (NW Greece), we attempted to derive the crustal thickness from the existing gravity data. This was achieved by employing spectral techniques of analysis of the Bouguer gravity map of the area. 
A series of 8 overlapping grids of maximum allowed grid size $(160 \times 160 \mathrm{~km})$, were used in an attempt to increase resolution while retaining the capacity to discern deeper sources. For each grid, Moho depths were established from the slope of the log-power radial spectrum at the lower end of the wavenumber band.

Crustal thickness in the area was found to vary from 31 to $39 \mathrm{~km}$, and this result is in good agreement with the results obtained employing seismological data.

\section{REFERENCES}

BHATTACHARYYA, B. K. and L. Leu, Spectral analysis of gravity and magnetic anomalies due to two-dimensional structures, Geophysics, 40, 993-1013, 1975.

Bose, P. K. and B. J. SEnGuPTA, Spectral analyses of offshore magnetic data for computing depths to the basement rocks. Mar. Geophys. Res., 6, 245-256, 1984.

BurchField, B., Evolution tectonique du system Alpin en Mediterranee. Poinconnement et ecrasement. Bull. Soc. Geol. Fr., 19, 437-460, 1980.

Dimitriadis, K., G.-A. Tselentis, and K. Thanassoulas, A basic program for 2-D spectral analysis of gravity data and source-depth estimation, Comput. Geosci., 13, S49-S60, 1987.

Drakopoulos, J. K. and N. D. Delibasis, On the mechanism of some earthquakes in the area of western Greece and the stress producing them, Proc. 13th Eur. Seism. Com. Special Issue of Techn. and Ec. Studies, Bucharest D-Ser. Geoph. Prosp., 10, 169-192, 1974.

Green, A. G., Magnetic profile analysis, Geophys. J. R. Astron Soc. London, 30, 393-403, 1972.

HaHN, A., E. G. Kind, and D. C. Mishra, Depth estimation of magnetic sources by means of Fourier amplitude spectra. Geophys. Prospect., 24, 287-308, 1976.

INOUE, $\mathrm{H}$., A least squares smooth fitting for irregularly spaced data-Finite element approach using the cubic B-spline basis, Geophysics, 51, 2051-2066, 1986.

Institute Francais du Petrole (I.F.P.), Etude Geologique de l'Epire, I.G.M.E., Athens, 1966.

KARACOSTAS, G., Crustal structure from seismological investigations in the area of Greece, Ph.D. Diss. Seismological Lab., Thessaloniki University, 133 pp., 1982.

King, G., G.-A. Tselentis, P. Molnar, S. Roecker, H. Sinvhal, C. Sufleris, and J. Stock, Microearthquake seismicity and active tectonics of northwestern Greece, Earth Planet. Sci. Lett., 66, 279-288, 1983.

Le Pichon, X. and J. Angelier, The Hellenic arc and Trench system: A key to the neotectonic evolution of the E. Mediterranean area, Tectonophysics, 60, 1-42, 1979.

MAKris, J., Geophysical Investigations of the Hellenides, Geophys. Eiyzel-schr., Vol. 34, Hamburg University, 126 pp., 1977.

McKenziE, D. P., Active tectonics of the Alpine-Himalayan belt: The Aegean sea and surrounding regions, Geophys. J. R. Astron. Soc., 55, 217-254, 1978.

Mercier, J., N. D. Delibassis, A. Gauthier, J. Jarrige, F. Lemeille, M. Sebrier, and D. Sorel, La neotectonique de l'arc Aegeen, Rev. Geol. Dyn. Geogr. Phys., 2, 67-92, 1979.

Mishra, D. C. and L. B. Pedersen, Statistical analysis of potential fields from subsurface reliefs, Geoexploration, 19, 247-265, 1982.

Negi, J. G., P. K. Agrawal, and K. N. N. Rao, Three dimensional model of the Koyna area of Maharashtra State (India) based on the spectral analysis of aeromagnetic data, Geophysics, 48, 964-974, 1983. 
Pal, P. C., K. K. Khurana, and P. Unnikrishnan, Two examples of spectral approach to source depth estimation in Gravity and Magnetics, Pageoph, 17, 772-783, 1979.

Papazachos, B., A. Kiratzi, P. Hatzidimitriou, and A. Rocca, Seismic faults in the Aegean area, Tectonophysics, 106, 71-85, 1984.

Paquin, C., J. Bloyet, and C. Angelidis, Tectonic stresses on the boundary of the Aegean domain. In situ measurements by overcoring, Tectonophysics, 110, 145-150, 1984.

SPECTOR, A., Spectral analysis of aeromagnetic maps, Ph.D. thesis, University of Toronto, 1968.

SPECTOR, A. and F. S. GRANT, Statistical models for interpreting aeromagnetic data, Geophysics, 25, 293-302, 1970.

SwaIN, C. J., A Fortran IV program for interpolating irregular spaced data using the difference equations for minimum curvature, Comput. Geosci., 1, 231-240, 1976.

TReitel, S., W. G. Clement, and R. K. Kaul, The spectral determination of depths to buried magnetic basement rocks, Geophys. J. R. Astron. Soc., 24, 415-428, 1971.

Tselentis, G.-A. and J. Drakopoulos, Crustal structure in W. Greece as obtained from the analysis of surface waves, Pure Appl. Geophys., 1988 (in press). 